\title{
Integration of Social Resources: Joint Command System in Large-Scale Emergencies
}

\author{
Xiangtao Yan*, Zhiyong Zhang \\ National University of Defense Technology, Changsha, China \\ Email: "yanxiangtao@nudt.edu.cn
}

Received 20 October 2014; revised 2 December 2014; accepted 9 December 2014

Copyright (C) 2014 by authors and Scientific Research Publishing Inc.

This work is licensed under the Creative Commons Attribution International License (CC BY). http://creativecommons.org/licenses/by/4.0/

c) (i) Open Access

\begin{abstract}
Command system is the core part in responding large-scale emergencies. Central government needs to integrate social resources in constructing command system rapidly. Social resources from military, enterprises, government and non-government organization should be integrated in command system which includes situational awareness system, communication system and decision system. The architectures of these systems are described in turn. Military command system should be the main part and backbone in large-scale emergencies.
\end{abstract}

\section{Keywords}

Command System, Large-Scale Emergencies, Social Resources, Military-Civil Integration, China

\section{Introduction}

Large-scale emergencies include natural emergencies, such as flood, ice storm, earthquake and tsunami. And they also include social emergencies, such as terrorist attacks, riot and large-scale accidents [1]. Large-scale emergencies are unpredictable, destructive and urgency. So the whole society should gather social resources to respond them. Joint command system should be constructed to manage, command, control and adjust these resources. So it is necessary to integrate social resources in responding large-scale emergencies.

Governments the world over take it seriously to construct joint command system in large-scale emergencies. USA founded the Federal Emergency Management Agency (FEMA) which was under the direct control of president in 1979. After 9/11, USA government founded the Department of Homeland Security (DHS) which integrated the function from 22 departments, such as FEMA, CIA and Nuclear Incident Response Team [2].

${ }^{*}$ Corresponding author. 
Russia founded the Ministry of the Russian Federation for Affairs for Civil Defense, Emergencies and Elimination of Consequences of Natural Disasters (EMERCOM) in 1994, which was the key role in responding the emergencies all over the Russia [3]. Japan founded the Minister of State for Disaster Management in 2001, which organized the emergencies responding system from central government to local government. If there is a large-scale emergency occurring, the Prime Minister will become the highest commander to operate the command system in Central Disaster Management Council [4].

China has improved the ability to respond large-scale emergencies significantly after Wenchuan Earthquake. The State Council Headquarters for Resisting Earthquake and Providing Disaster Relief was founded to organize the relief work. The Premier Jiabao Wen was the lead the headquarters. PLA was an important part in this headquarters and built upon the positive imagery through great efforts [5]. But as we know, the leadership team is a temporary organization which will be canceled after the disaster. So China needs to construct a stable command system for large-scale emergencies so as to integrate the social resource to respond better.

\section{The Architecture of Joint Command System}

Command in emergencies is a special kind of command activity which includes the leading, planning, dispatching and controlling in rescue subjects, such as government departments, army troops, polices, healthy branches, enterprises and NGOs. Command in emergencies is based on communication equipment. Joint Command System (JCS) in large-scale emergencies is the center of command relationship and command equipment, and the most important material base in emergencies. According to the information processing, JCS includes three parts that are situational awareness system, communication system, command and decision system, which is shown in Figure 1.

There are four kinds of facilities in situational awareness system. The first kind is military intelligence facilities stationed in emergencies' position. The second kind is civic intelligence facilities stationed in emergencies, such as geological monitoring network, weather network, branch of government departments, communication facilities, etc. The third kind is the military sensor networks in temporary mobilization. The fourth kind is the monitoring system which central government appoints to emergency temporarily, such as satellite remote sensing system, emergency detection facilities, etc. The duty of situational awareness system is collecting the information in emergencies, which includes people in trapped, people in injuries and deaths, possible position and strength of secondary disasters, position of rescue troops, etc. It will support the whole system in intelligence for commanding of emergencies.

Communication system is the basic infrastructure in situational awareness system and command and control system. It is also the bridge of these two systems. Some communication method will be destroyed in large-scale emergencies. So some temporary communication equipment must be started. Especially, military communication system will play a key role in large-scale emergencies. So army and civic branch must train together in normal

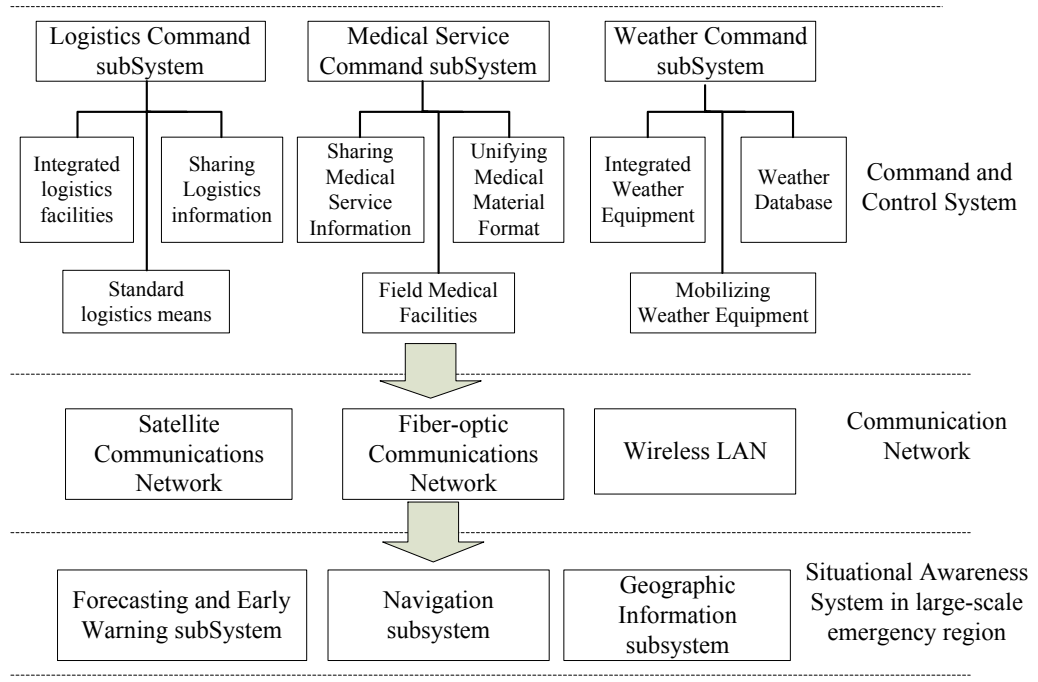

Figure 1. The architecture of joint command system in emergency. 
times. The frequencies, interfaces and protocols of military communication system and civic communication system need to be set in contingency plan.

The functions of command and control system are dispatching rescue troops, materials transportation, casualty treatment, disaster prediction, information releasing, experts consulting. As we know, both army and government branches have systematic and rigid command system. So, army and government and other social organizations need cooperate in large-scale emergencies. The cooperating method is shown in Table 1.

In general, we should integrate the existing situation and technology demand of all kinds of command system in JCS designing. We should balance several objectives of JCS, such as information sharing, flexible controlling, seamless connection, minimize the reaction time, and free access to the network. The structure of these systems will be described as follows.

\section{Situational Awareness System in Large-Scale Emergency Region}

For improving the ability of fast response and reliability of situational awareness system, the monitoring detection equipment should connect adequately to share information and mutual confirmation. There are several important subsystems in Situational Awareness System, including forecasting and early warning subsystem, navigation subsystem and geographic information subsystem.

\subsection{Forecasting and Early Warning Subsystem}

This is an important part in Situational Awareness System and an important link in responding large-scale emergencies. We can greatly lower the risk of life and property in emergency region when we can forecast and early warn the disasters. He has reported a successful forecasting event in Wenchuan Earthquake. When there was a barrier lake named Tangjiashan Lake appeared in earthquake region, forecasting and early warning subsystem analyzed the result of flooded area after exploding the dam. So, China avoided another serious lose in this event [6]. The forecasting information of aftershock has played a key role in reassuring people and avoiding lose in disaster.

\subsection{Navigation Subsystem}

Navigation subsystem is very important to locate the rescue troops and people in trapped. It can also supply the emergence communication. GPS is the most popular navigation system in emergency rescue system. But in Wenchuan Earthquake, the Beidou-1 Navigation was the bright star. Beidou-1 Navigation is developed all by Chinese researcher. It is the symbolic achievements after reforming and opening in China. The demand to develop this system is for large-scale emergencies. According to the function in Wenchuan Earthquake, Beidou-1 Navigation will become the main navigation system in future emergencies rescue [7]. Its functions are shown below:

- Supplying the monitor and locating information in emergencies. The traffic, power system and communication will collapse possibly in emergencies. So great difficulty will occur in the rescue command. Navigation equipment has locating and communication function. So stationary and mobile navigation equipment can send the information about emergency region to command center;

- Remote monitor and warning. We can use the professional sensor in dangerous region and link the sensor the navigation equipment. When disasters happen, the navigation equipment will warn to command center through short messages;

- Public intelligence services. Navigation subsystem will send short message to calm down the people in trapped and recover people's motion. It also can supply the weather and traffic information to rescue troop to improve the rescue efficiency.

Table 1. Cooperation method of emergency command in each level.

\begin{tabular}{cl}
\hline Level & Content of cooperation \\
\hline Strategy level & $\begin{array}{l}\text { Jointly participation and decision-making of government } \\
\text { branches and army troops }\end{array}$ \\
Operation level & Joint operation in emergency command \\
Technology level & Standards, processes, terms \\
\hline
\end{tabular}




\subsection{Geographic Information Subsystem}

GIS is the core platform in processing and analyzing fundamental geographic information and disaster thematic information. It includes several modules, such as automatic data exchanging, information service engine, emergency scene service, etc. [8]. Its functions are shown as follows:

- Quickly estimating the property losing and people injuries and deaths according to the basic data. Emergencies commander can use GIS information to judge the scale and trend of disaster;

- Quickly forming the rescue reservation data. According to the basic data, commander can draw up the rescue plan. GIS will supply the information about which kind of rescue branch and how many branches are needed, how many rescue branches, which kind of rescue material and how many materials are needed, where people should evacuate, and so on;

- Demonstrating all kinds of data in quantify and graphical form. It will improve the rationality and pertinence of rescue activities.

\section{Communication System}

It is the base of command system operating smoothly that social communication system will be operated unblocked and intermingle. Townsend, the assistant to the President for Homeland Security and Counterterrorism, summarized the lesson in Hurricane Katrina. He pointed that army and National Guard and government emergency branches had some problems in cooperation because of the different communication equipment and lack of joint training [9]. So it is very important to premeditate to integrate all kinds of communication systems in emergency plan. According to the special situation in emergency, satellite communications network, fiber-optic communications network and Wireless LAN can meet the demand in large-scale emergencies.

\subsection{Satellite Communications Network}

Satellite communications network will be used to connect On-Scene-Commanders center and commanders back at headquarters. As we know, original communication systems will maybe be destroyed in emergency. And we can't predict the exact position of emergencies. Satellite communication network is better than other communication methods in reliability and mobility. The advantages of satellite communications network are shown as follows:

- Stable and reliability of communication;

- Supporting massive and frequent and real-time multimedia information transferring;

- Long-distance communication;

- One-to-one communication.

\subsection{Fiber-Optic Communications Network}

Fiber-optic communications network will become the backbone network of JCS. It not only has high-capacity, but also has high reliability and anti-disturbing. We can preset communication ports in possible emergencies region and position in JCS's construction process. The communication between all nodes will rely on fiber-optic communication network in emergencies. The rescue subjects will mobilize around important position according to their assignment and choose communication port to enter the network which closes to their position.

\subsection{Wireless LAN}

Wireless LAN will be the main communication method in emergency scene. There will be so many rescue teams in emergency scene that we expect that the communication system can support the real-time and all-direction information exchange. Every rescue team which has been authorized will enter the Wireless LAN in emergency scene and work with their colleagues [10]. The advantages of Wireless LAN are shown as follows:

- Timely and accurate information transferring;

- Supporting massive and frequent communication;

- Strong enough signal and overcoming the obstacles;

- Range of communication is limited in emergency scene;

- Supporting command center to contact with multi-teams. 


\section{Command and Control System}

Command and Control (C2) System includes some subsystem, such as Rescue troop command subsystem, material transport subsystem, person curing subsystem, information releasing subsystem and experts consulting subsystem. There are several subsystems which should integrate the social resource immediately.

\subsection{Logistics Command Subsystem}

Emergency logistics is a kind of special logistics activity which aims to supply material in emergency and pursue the maximum of time-efficiency and the minimum of disaster losing. Comparing with regular logistics, emergency logistics has some features, such as unexpectedness, urgency, uncertainty, weak-economy and government involvement [11]. We should design some important function in emergency logistics command subsystem as follows:

- Organization of emergency logistics. It will supply the means to collect and analyze situation, to draw up the logistics plan, to organize logistics business, to coordinate logistics conflict in emergency;

- Holding the ability of emergency logistics processing. It will gain and process the logistics information about the quantity and quality and location of emergency material and equipment. It also includes the information about transportation ability and storage ability in emergency logistics distribution center;

- Displaying of logistics resources. It will display the logistics information about emergency materials, funds, facilities and space;

- Dynamic controlling and commanding. It will manage the transportation process;

- Business processing of emergency logistics. It will include statistics, application, planning, allocation, accounting and documents handling;

- Aided decision-making. It will supply all kinds of decision-making models in emergency logistics, which will help commanders and organizations to optimize decision-making and choose alternatives.

Furthermore, logistics command subsystem will be allocated to each social part to improve the logistics efficiency in large-scale emergencies. The models and standards of container and tray will be set in advance. The means of transportation will be unified. The material coding and recognizing system will be constructed in advance. Logistics training should be embedded in emergency rescue training.

\subsection{Medical Service Command Subsystem}

Military medical service branches have become the main force in Chinese emergencies medical service after SARS and Wenchuan Earthquake [12]. They have strict discipline and excellent mobility. So they can be allocated to any region and any situation. So, military medical services will serve as the main part of medical service command subsystem. This subsystem should absorb the social medical service ability in training and in emergencies. Headquarter of medical service command need to know the rescue procedures and allocate professional persons and material to special position. Advanced information technology and network communication should be applied in this subsystem so as to construct agile command system.

\subsection{Weather Command Subsystem}

Weather command subsystem will integrate civil and military weather forecast ability. It will report the weather information about monitoring, early warning and forecast in large-scale emergencies. It also needs to evaluate the influence scale and duration of disaster [13]. After integrating social resource, a state should establish an integrated weather database system, which will store information of reported events, forecast and monitor in emergencies.

\section{Conclusion}

Joint Command System in large-scale emergency is a very important infrastructure of a country. This article described the architecture of this system from three levels: situational awareness system, communication system, and command and decision system. Situational awareness system will supply the necessary information about large-scale emergencies. So it will spray in the whole emergency region. Communication system severs as the nerve system in JCS and links every part to respond the emergency. Command and decision system will operate 
the whole rescue function according to transfer material and information to proper place in time. Social resources will be concentrated to these three systems and integrated for responding large-scale emergencies. We should design the subsystems in detail based on this architecture. So we can improve the responding ability and reduce the loss in emergencies.

\section{References}

[1] Liu, L. (2008) New Generation Emergency Communication Network Meeting C4I Demand. Policy Research in Communication Technologies, 5, 1-10.

[2] Department of Homeland Security (2012) Creation of the Department of Homeland Security. http://www.dhs.gov/creation-department-homeland-security

[3] EMERCOM (2008) Statistics of Emergencies in the Russian Federation in 2008. http://en.mchs.ru/document/90518

[4] Cabinet Office, Government of Japan (2011) Disaster Management in Japan. http://www.bousai.go.jp/1info/pdf/saigaipanf_e.pdf

[5] Mulvenon, J. (2008) The Chinese Military's Earthquake Response Leadership Team. China Leadership Monitor, 25, $1-8$.

[6] He, Y. (2008) The Construction of State Emergency Platform System: From Wenchuan Earthquake Perspective. Office Operation, 7, 32-33.

[7] Zhao, K. (2008) Beidou Navigation System Practice and Enlightenment in the Sichuan Earthquake Relief. Gnss World of China, 4, 45-48.

[8] Guo, J. (2008) Preliminary Construction in Xinjiang Earthquake Emergency Basic Geographic Information Platform. Geomatics Technology and Equipment, 3, 7-10.

[9] Townsend, F.F. (2006) The Federal Response To Hurricane Katrina: Lessons Learned. The White House, Washington DC.

[10] Wang, M., Wu, L. and Wang, X. (2008) Application of Wireless LAN to the Emergency Rescue Based on IEEE 802.11. China Safety Science Journal, 9, 111-116.

[11] Jiang, Y., Yan, H. and Wang, F. (2007) Emergency Logistics and Integration of Military Logistics. Journal of Logistical Engineering University, 1, 88-91.

[12] Cai, B., Huang, L. and Sun, Y. (2008) Army Public Health Emergencies Emergency Command System Platform Construction Research and Idea. China Digital Medicine, 12, 41-43.

[13] Zhai, W. (2008) Research on Construction of Meteorological Information Platform of Emergency Management. East China Economic Management, 11, 156-158. 
Scientific Research Publishing (SCIRP) is one of the largest Open Access journal publishers. It is currently publishing more than 200 open access, online, peer-reviewed journals covering a wide range of academic disciplines. SCIRP serves the worldwide academic communities and contributes to the progress and application of science with its publication.

Other selected journals from SCIRP are listed as below. Submit your manuscript to us via either submit@scirp.org or Online Submission Portal.
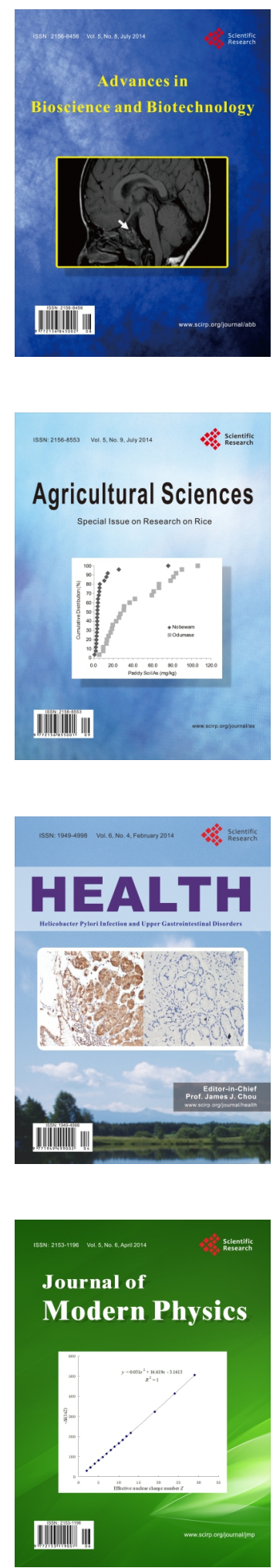
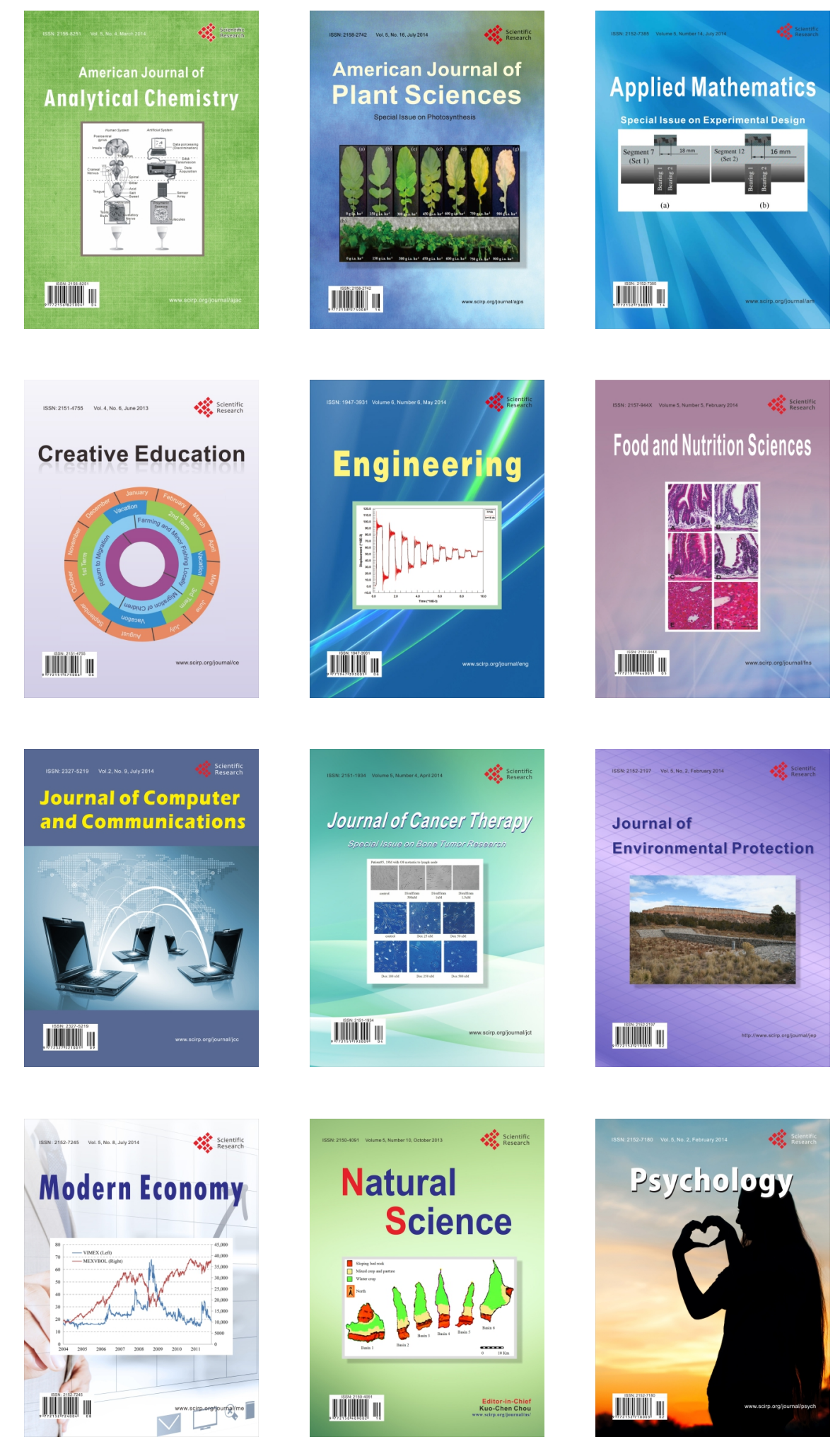